\title{
Análise microbiológica do útero e da vagina em cutias nulíparas e não-nulíparas (Dasyprocta azarae)
}

\author{
Leandro Luis Martins ${ }^{1}$ \\ Fabrício Singaretti de Oliveira ${ }^{2 *}$ \\ Márcia Rita Fernandes Machado ${ }^{1}$ \\ Renato Pariz Maluta ${ }^{3}$ \\ Sandra Regina Caldeira Mendes ${ }^{4}$ \\ Fernando Antonio de Ávila ${ }^{3}$ \\ ${ }^{1}$ Departamento de Morfologia e Fisiologia Animal \\ Universidade Estadual Paulista, Jaboticabal - SP, Brasil \\ ${ }^{2}$ Departamento de Medicina Veterinária, Universidade Estadual de Maringá, Campus Umuarama \\ Caixa Postal 65, CEP 87501-970, Umuarama - PR, Brasil \\ ${ }^{3}$ Departamento de Patologia Veterinária, Universidade Estadual Paulista, Jaboticabal - SP, Brasil \\ ${ }^{4}$ Zoológico Municipal de Catanduva, Catanduva - SP, Brasil \\ * Autor para correspondência \\ singaretti@ig.com.br
}

Submetido em 01/02/2012

Aceito para publicação em 25/06/2012

\section{Resumo}

Os órgãos genitais dos animais domésticos geralmente são colonizados por diversos microrganismos. O objetivo deste trabalho é descrever a microbiota do útero e da vagina em cutias nulíparas e não nulíparas, pertencentes ao Zoológico Municipal de Catanduva -SP. Durante ovariossalpingohisterectomia, colheu-se material para a análise microbiológica mediante a introdução de swabs estéreis na vagina e em cada corno uterino. Observou-se presença de Proteus sp. no material uterino de apenas um dos animais. No material vaginal de todos os animais constatou-se a presença de várias bactérias (Proteus sp., Escherichia coli, Citrobacter sp., Pseudomonas sp. e Staphylococcus sp.) e leveduras. A microbiota vaginal e uterina de cutias apresenta padrão de colonização diferente daquela observada em outros animais domésticos, na mulher e na rata.

Palavras-chave: Lagomorfo; Microbiota; Roedor; Trato reprodutivo

\section{Abstract}

Microbiological analysis of the uterus and vagina of nulliparous and non-nulliparous agoutis (Dasyprocta azarae). The genital organs of domestic animals are usually colonized by several microorganisms. This paper aims at describing the uterine and vaginal microbiota of nulliparous and non-nulliparous agoutis, which belong to the Catanduva City Zoo, Sao Paulo, Brazil. During the procedure of ovariosalpingohisterectomy, material was collected for microbiological analysis through the introduction of sterile swabs in the vagina and in each uterine horn. The presence of Proteus sp. was observed in the uterine material of only one animal. In the vaginal material of all animals, several bacteriae (Proteus sp., Escherichia coli, Citrobacter sp., Pseudomonas sp., and Staphylococcus sp.) and yeasts were found. The vaginal and uterine microbiota of agoutis presents a colonization pattern different from that observed in other domestic animals, in women, and in female rats.

Key words: Lagomorph; Microbiota; Reproductive tract; Rodent 


\section{Introdução}

A cutia (Dasyprocta azarae), roedor da família Dasyproctidae, apresenta peso entre 1,5 a $2,8 \mathrm{~kg}$ e se alimenta de folhas, raízes, flores, fungos, sementes, especialmente de frutos caídos no solo (KONEMAN et al., 2007). São animais que vivem em matas, capoeiras e áreas cultivadas, nas Américas Central e do Sul (MOLLINEAU et al., 2008) e exercem grande contribuição ao equilíbrio ecológico, pois atuam com agentes distribuidores de sementes de árvores nativas por diversos quilômetros (SMYTHE, 1978), apresentando potencial zootécnico (PINHEIRO et al., 1989).

A flora vaginal dos animais domésticos é composta de uma mistura dinâmica de microorganismos aeróbicos, anaeróbicos facultativos e estritamente anaeróbicos, entretanto, constantemente, novas linhagens são introduzidas a este meio. Durante o ciclo estral, várias populações de microorganismos apresentam enzimas que lhes permitem ou preparam para sobreviver e multiplicar-se no ambiente vaginal. O aumento do glicogênio, que ocorre em algumas fases do ciclo reprodutivo favorece o predomínio de organismos acidófilos entre o grupo heterogêneo que constitui a flora vaginal normal (HAFEZ; HAFEZ, 2004).

A cutia constitui uma espécie com crescente interesse científico, fato que pode ser observado em diversos artigos recentes sobre determinação da taxa metabólica basal (BRITO et al., 2010), anatomia dos esqueletos axial (OLIVEIRA et al., 2009a) e do apendicular (OLIVEIRA et al., 2009b), além de anestesia (MARTINS et al., 2011a), cirurgia (MARTINS et al., 2010), morfologia uterina (MARTINS et al., 2011b) e determinação da microbiota intestinal (OLIVEIRA et al., 2009c).

O objetivo deste trabalho foi determinar a flora microbiana do útero e da vagina em cutias nulíparas e não nulíparas.

\section{Material e Métodos}

Esta pesquisa foi aprovada pela Comissão de Ética e Bem Estar Animal (CEBEA) da FCAV, Campus de Jaboticabal, UNESP, protocolo $\mathrm{n}^{\circ}$ 008581-07, de acordo com os Princípios Éticos na Experimentação Animal, adotado pelo Colégio Brasileiro de Experimentação Animal (COBEA).

Foi analisada a microbiota de material colhido do útero e vagina, durante procedimento de ovariossalpingohisterectomia, em oito cutias fêmeas, quatro nulíparas e quatro não-nulíparas, adultas, pesando 2,57 $\pm 0,44 \mathrm{~kg}$, pertencentes ao Zoológico Municipal "Missina Palmeira Zancaner", município de Catanduva, SP.

Após realização de pequena incisão, swabs estéreis foram introduzidos na vagina e em cada corno uterino. Em seguida, os swabs com o material colhido foram colocados em salina estéril e refrigerados a $7^{\circ} \mathrm{C}$ e encaminhados para processamento laboratorial. As amostras foram semeadas em ágar Sabouraud, específico para o crescimento de fungos, em ágar BHI (ágar infusão cérebro coração), inespecífico ao crescimento de microorganismos, em Ágar MacConkey (para isolamento seletivo de microorganismos gram negativos) e incubadas por $48 \mathrm{~h}$ a uma temperatura de $36^{\circ} \mathrm{C}$. Em seguida, as colônias isoladas foram semeadas em meio TSI (tríplice açúcar e ferro) e foram examinadas pelo método de gram.

\section{Resultados e Discussão}

Foi encontrada microbiota na vagina, tanto de animais nulíparos como não-nulíparos. Em apenas um dos animais não-nulíparos verificou-se microrganimo uterino. Na vagina de sete dos oito animais analisados, foram observadas bactérias e leveduras (Tabela 1).

Embora alguns gêneros da flora microbiana vaginal diferiram entre cutias nulíparas e não-nulíparas, a colonização desta região do trato genital das fêmeas se mostrou evidente, diferentemente do observado no útero, órgão que apresentou colonização em apenas um animal não-nulíparo.

Os hormônios possuem um papel inusitado na proteção do sistema genital contra doenças, sobretudo no tocante à presença e à atividade das células fagocitárias, cuja ocorrência varia dependendo da fase do ciclo reprodutivo (HIRSH, 2003; QUINN et al., 2005), o que pode estar relacionado à ausência de microorganismos no útero e na vagina de um dos animais deste trabalho. 
TABELA 1: Registro da microbiota no útero e na vagina de cutias nulíparas e não-nulíparas.

\begin{tabular}{l|c|c}
\hline $\begin{array}{c}\text { Número dos } \\
\text { animais }\end{array}$ & $\begin{array}{c}\text { Microbiota } \\
\text { uterina }\end{array}$ & Microbiota vaginal \\
\hline 1 (nulípara) & Ausente & Pseudomonas sp. \\
4 (nulípara) & Ausente & Escherichia coli e Levedura \\
6 (nulípara) & Ausente & Ausente \\
8 (nulípara) & Ausente & Staphylococcus $\mathrm{sp}$. \\
2 (não-nulípara) & Ausente & Citrobacter $\mathrm{sp}$. \\
3 (não-nulípara) & Ausente & Escherichia coli \\
5 (não-nulípara) & Proteus & $\begin{array}{c}\text { Levedura, Proteus } \mathrm{sp} ., \\
\text { Escherichia coli }\end{array}$ \\
\hline
\end{tabular}

Embora o útero não-prenhe seja relativamente resistente à infecção (QUINN et al., 2005), verificou-se a presença de Proteus sp. no útero de um dos animais não-nulíparos avaliados, diferentemente do reportado em coelhas, que possuem útero frequentemente colonizado, principalmente por Staphylococcus sp. (JACQUES et al., 1986). O gênero Proteus também já foi identificado em ratas em idade reprodutiva, embora não se tenha sido especificado o local exato deste trato genital desses animais (LARSEN et al., 1976).

Diferentemente do observado na microbiota vaginal da coelha (JACQUES et al., 1986), cadela (BABA et al., 1983) e da mulher (BARTLETT; POLK, 1984), que apresentam grande quantidade de Staphylococcus sp., este gênero foi observado apenas em $25 \%$ dos casos analisados, em igual proporção entre nulíparas e nãonulíparas. O gênero Pseudomonas foi pouco observado na vagina das cutias ( $12,5 \%$ dos casos), contrariamente ao observado na coelha (JACQUES et al., 1986), que apresenta esse gênero como um dos mais comuns na microbiota vaginal e cervical.

Não foi observado Streptococcus sp., um microorganismo muito comum na vagina de coelhas (JACQUES et al., 1986) e em ratas (LARSEN et al., 1976), cadelas (BABA et al., 1983) e babuínas (SKANGALIS et al., 1979).

A partir dos resultados, é possível concluir que a microbiota vaginal e uterina de cutias apresenta padrão de colonização diferente daquela observada em animais domésticos, na mulher e na rata.

\section{Referências}

BABA, E.; HATA, H.; FUKATA, T.; ARAKAWA, A. Vaginal and uterine microflora of adult dogs. American Journal of Veterinary Research, Schaumburg, v. 44, p. 606-609, 1983.

BARTLETT, J. G.; POLK, B. F. Bacterial flora of the vagina: quantitative study. Reviews of Infectious Diseases, New Jersey, v. 6, p. 67-72, 1984.

BRITO, H. F. V.; LANGE, R. R.; PACHALY, J. R. DECONTO I. Determinação da taxa metabólica basal em cutias, Dasyprocta azarae, por calorimetria indireta. Pesquisa Veterinária Brasileira, Rio de Janeiro, v. 30, n. 6, p. 471-478, 2010.

HAFEZ, B.; HAFEZ, E. S. E. Reprodução animal. 7. ed. Barueri: Manole, 2004. 27 p.

HIRSH, D. C. O trato genital como um habitat microbiano. In: HIRSH, D. C.; ZEE, Y. C. (Ed.). Microbiologia Veterinária. Rio de Janeiro: Guanabara Koogan, 2003. p. 179-180.

JACQUES, M.; OLSON, M. E.; CRICHLOW, A. M.; OSBORNE, A . D.; COSTERTON, J. W. The normal microflora of the female rabbit's genital tract. Canadian Journal Veterinary Research, Ottawa, v. 50, p. 272-274, 1986.

KONEMAN, E. W.; ALLEN, S. D.; JANDA, W. M.; SCHRECKENBERGER, P. C.; LANGE, R. R.; SCHMIDT, E. M. S. Tratado de animais selvagens. São Paulo: Roca, 2007. 476 p.

LARSEN, B.; MARKOVETZ, A. J.; GALASK, R. P. The bacterial flora of the female rat genital tract. Proceedings of the Society for Experimental Biology and Medicine, Cambridge, v. 151, p. 571-574, 1976

MARTINS, L. L.; BIAGIONI, M. M.; OLIVEIRA, F. S.; TONIOLLO, G. H.; PACHECO, M. R.; MACHADO, M. R. F. Morfologia do útero de cutias nulíparas e não nulíparas. Arquivo Brasileiro de Medicina Veterinária e Zootecnia, Belo Horizonte, v. 63, n. 2, p. 326-332, 2011 b.

MARTINS, L. L.; OLIVEIRA, F. S.; RODRIGUES, V.; TONIOLLO, G. H.; MACHADO, M. R. F. Ovariossalpingohisterectomia em cutias (Dasyprocta azarae Lichtenstein, 1823): uso de técnica convencional. PUBVET, Londrina, v. 4, n. 779, sem paginação, 2010 .

MARTINS, L. L.; RODRIGUES, V.; OLIVEIRA, F. S.; TONIOLlO, G. H.; PAUlONI, A. P.; MACHADO, M. R. F. Anestesia epidural em cutias (Dasyprocta azarae) submetidas à ovariossalpingohisterectomia. Biotemas, Florianópolis, v. 23, p. 177-181, 2011a.

MOLlineAU, W. M.; ADOGWA, A. O.; GARCIA, G. W. Spermatozoal morphologies and fructose and citric acid concentrations in agouti (Dasyprocta leprorina) semen. Animal Reproduction Science, Dublin, v. 105, n. 3, p. 378-383, 2008.

OLIVEIRA, F. S.; FRIAS, D. F. R.; KOZUSNY-ANDREANI, D. I.; MARTINS, L. L.; DELFINI, A.; TONIOLLO, G. H. Microbiota intestinal em cutias criadas em cativeiro. Ciência Animal Brasileira, Goiânia, v. 10, n. 2, p. 660-662, 2009c.

OLIVEIRA, F. S.; MARTINS, L. L.; PAULONI, A. P.; MACHADO, M. R. F.; TONIOLLO, G. H.; CANOLA, J. C. Descrição anátomoradiográfica do esqueleto axial da cutia (Dasyprocta azarae Lichtenstein, 1823). Ars Veterinaria, Jaboticabal. v. 25, p. 20-23, 2009a. 
OLIVEIRA, F. S.; MARTINS, L. L.; PAULONI, A. P.; TONIOLLO, G. H.; CANOLA J. C.; MACHADO, M. R. F. Descrição anátomoradiográfica do esqueleto apendicular da cutia (Dasyprocta azarae Lichtenstein, 1823). Ars Veterinaria, Jaboticabal, v. 25, p. 24-27, 2009b.

PINHEIRO, J. J. P.; ANDRADE, S. A.; CUNHA, J. N. Preservação e exploração de animais silvestres nativos: preá, cutia e moco. Caatinga, Mossoró, v. 6, p. 28-49, 1989.

QUINN, P. J.; MARKEY, B. K.; CARTER, M. E.; DONELLY, W. J.; LEONARD, F. C.; Microbiologia Veterinária e Doenças Infecciosas. Porto Alegre: Artmed, 2005. $437 \mathrm{p}$

SKANGALIS, M.; SWENSON, C. E.; MAHONEY, C. J.; O'LEARY, W. M. The normal microbial flora of the baboon vagina. Journal of Medical Primatology, Copenhagen, v. 8, p. 289-297, 1979.

SMYTHE, N. The natural history of the Central American agouti (Dasyprocta punctata). Smithsonian Contributions to Zoology, Washington, v. 257, p. 1-52, 1978. 